\title{
China English and its implications for EFL teaching in China
}

\author{
Bihua Tan \\ College of Foreign Languages, China Three Gorges University, Yichang of Hubei Province, China
}

Email address:

78764778@qq.com

\section{To cite this article:}

Bihua Tan. China English and Its Implications for EFL Teaching in China. Education Journal. Vol. 3, No. 6, 2014, pp. $340-344$. doi: 10.11648/j.edu.20140306.13

\begin{abstract}
Since the term China English was ever proposed, debates on it have never suspended in the academic world concerned. Nevertheless, both scholars in the PRC and abroad maintain that China English has become an objective existence. Within the framework of a review of the literature sources pertaining to this localized language phenomenon, this article distinguishes China English with another analogous terminology Chinese English, and adduces the salient linguistic features of the former at four levels (phonology, lexis, syntax, and discourse). Drawing upon the analytical synthesis of the generic attributes of China English, the paper then extracts pedagogical implications to inform EFL teaching in mainland China. The paper closes with a proposal of some tentative suggestions for future research in this realm.
\end{abstract}

Keywords: China English, Linguistic Features, Chinese EFL Teaching Context

\section{Introduction}

Globalization has exerted profound influence on varied dimensions (economic, political, cultural, etc.) of any social entity involved. This rapid globalizing process stimulates the promotion of the English language which in turn results in its localization and nativization (Mckay, 2012). As one indispensable component of the global Englishes family, China English has gradually exhibited its prominence and prevalence on the ground that the impact of the national power of China keeps mounting and there is an unprecedented demand for extensive cross-culture communications in diverse arenas. The development and promotion of China English can presumably decrease the rate of imperialization of the so-called Standard English given the largest number of English learners and potential users in China. Besides, the advancement of China English is an effective means to promote Chinese culture as well as preserves its unique identity during the process of globalization. Nevertheless, presently the effectiveness of cross-culture communication via English on the part of the Chinese English users is still far from being satisfactory, and to cultivate more and better qualified English learners with practical knowledge and skills still remains a thorny issue within the Chinese EFL college teaching context. It is under this circumstance that the topic I am going to address is of great theoretical and pragmatic significance for both the English teaching and research in China.

\section{China English Vs. Chinglish}

To begin with, it is of great significance and urgent necessity to label the variety of English learned and used in mainland China given that differing terms have been concurrently used by scholars to represent this localized language variety. And it is speculated that the consensus made on the terminology of this contextualized branch of global Englishes should legitimate its authority and promote its development. It is not difficult to note that both researchers in the PRC and abroad have endeavored to define this emergent language phenomenon and among all those competing counterparts, China English (see Ge, 1980; Jiang $\& \mathrm{Du}, 2003$ ) and Chinglish (see Niu \& Wolff,2003; Zhuang, 2000) maintain the highest profile. Wang (1991, p. 3) is the first scholar to define China English by saying that 'It is the English used by the Chinese people in China, being based on Standard English and having Chinese characteristics.' This initial endeavor propelled more scholars into the business, and $\mathrm{Li}$ (1993, p. 34) redefined it by asserting that 'China English is an English variety with normative English as its core to express Chinese specific phenomena in Chinese people's social life.' In a similar vein, Jin (2002, p. 72) described China English as 'a variety of English which has the international normative English as its core and which facilitates the transmission of Chinese-specific cultures, linguistic expressions, ideologies, and traditions in 
international settings.' A recent broad definition of China English was proposed by Pan (2005). Regarding his interpretation, China English refers to English used by the speakers with Chinese linguistic and cultural background. And he further claimed that this category of English efficiently functioned in cross-culture encounters and was acceptable on the part of English speakers. In addition to these, He and David (2009, p. 14) from Hong Kong University extended the study of China English with a quantitative analysis of the Chinese university students' attitude toward the acceptability of China English and firmly concluded that China English 'has the standard Englishes as its core but is colored with characteristic features of Chinese phonology, lexis, syntax and discourse pragmatics, and which is particularly suited for expressing content ideas specific to Chinese culture through such means as transliteration and loan translation.' With a comparative scrutiny of the preceding definitions, it is perceived that $\mathrm{He}$ and David's version is more comprehensive and adequate in that it takes the means of formation of China English into account and replaces the inaccurate 'normative English' with a more acceptable 'standard English'. Although the aforementioned stream of definitions generates slight variance in terms of the interpretation of this term, yet several common threads can be observed running through it. 1 The existence of China English is objective and inevitable. 2. China English has its distinctive linguistic features in alignment with its specific culture characteristics. 3. China English adheres to the rules of Standard English and meanwhile is loaded with a unique cultural flavor. 4. China English plays a positive part in cross-culture encounters and is beneficial for Chinese culture transmission and preservation.

If we say China English is the outcome of the positive transfer of the Chinese language, then Chinglish (which can also be verbalized as Chinese English) should be deemed as the product of the negative transfer of Chinese. According to Kirkpatrick and $\mathrm{Xu}$ (2002, p. 269), Chinglish is a term 'loaded with social stigma' and does not possess the same acceptability and prestige as China English does. Jiang (2002, p. 6) perceived Chinese English as 'bad English', or English beginners' language, and he asserted that this sort of language could be utilized as an interlanguage which merited improvement. In accordance with Yan's (2002, p. 204) theory, Chinglish is an 'unfinished product' of the individual Chinese yielded in the process of English acquisition. Instances of using 'Give you.' (instead of 'Here you are.') and 'Careful of your head!'(other than 'Mind your head!') are two typical examples of Chinglish with truncated use of English language by less proficient English learners. Based on the above analytical review, chances are that we eventually come to a clearer picture of some of the most noteworthy features of Chinglish, which are respectively are: 1.Chinglish is the truncated use of English language and the final product of the negative transfer of the native Chinese language. 2. Chinglish is an unstable individual language behavior and thus merits correction and improvement. 3 .
Both China English and Chinglish are branded with Chinese thinking and expression patterns, and thus sometimes it is difficult to differentiate one from the other.

\section{Linguistic Features of China English}

In this paper, like many other scholars, I would address the prevalent positive use of English in mainland China as 'China English', and in the following segments I would continue to synthesize the previous research fruits with an overview of some of the most salient linguistic features of this language kind. In recent decades, a range of scholars have uncovered the saliency of the linguistic features of China English, and they have agreeably examined its characteristics at four linguistic levels: phonology, lexis, syntax and discourse (see Deterding, 2006; He, 1999; Jiang, 1995; Jiang, 2001).

\subsection{Phonology}

Researchers argued that even Standard English would be embedded with some accents regardless of native or non-native speakers (e.g., $\mathrm{Hu}, 2007$; Widdowson, 1994). Nevertheless, it does not wipe out certain general phonological rules that can be traced amongst L2 speakers and foreign language users. And it is due to these universal rules that communications between individuals tend to be smooth-going and intelligible. Enlightened by Kirkpatrick (2007), I contend that it is impractical to claim that these phonological features are jointly consumed by users of China English from divergent regions. Despite this, we should never deny the presence of the following properties exhibited on the phonological level of China English: replacement of [v] with [w] and [S] with [s]; add-on of a final [ə] (He and David, 2009); confounding use of [1] and [n]; 'certain types of diphthong simplification' (He and David, 2009, p. 72), inappropriate reinforcement of weak forms and function words (Deterding, 2006), the substitute of [s] for [ $\theta]$ and [ð], and neglect of linking and intonation, etc.

Table 1. China English at the phonology level

\begin{tabular}{llllllll}
\hline Standard English & {$[v]$} & {$\left[\int\right]$} & {$[l]$} & {$[\theta]$} & {$[\partial]$} & {$[b]$} & {$[d]$} \\
China English & {$[w]$} & {$[s]$} & {$[n]$} & {$[s]$} & {$[s]$} & {$[b \partial]$} & {$[d \partial]$} \\
\hline
\end{tabular}

\subsection{Lexis}

There is great consensus among scholars that words and phrases are the main manifestations of the nativization of English in China given that 'the meanings generated by the lexicons are peculiar to China'(Jiang 2002, p. 13). The truth is that a fraction of these unique expressions have made its entry into Standard English and foreign experts are inclined to maintain that there is an objective existence of Chinese loan renderings in English (e.g., Bliss, 1966; Mawson, 1975).Two primary avenues through which culture-loaded lexicons are molded are respectively transliteration and loan translations (Bolton, 2003; Gao, 2001; He and David, 2009).

(a) Transliteration: A substantial number of pinyin 
expressions have gained access to Standard English given the untranslatability of the source language. These transliterated patterns can be conceived as the most conspicuous feature of China English. For example, Tuhao (newly-rich people with poor academic knowledge and taste), Chengguan (the official city inspectors notorious for their violent management), Dama (mainly middle-aged women obsessed with purchasing gold), etc. In addition to these, the Chinese proper names (mainly Chinese place names, figure names and article names) are largely reliant on this translating method.

(b) Loan translations: Loan translations occupy a prominent position in China English and they are coined via means of 'direct or word-by-word translation' (He and David, 2009, p. 73). Renderings such as Confucius Institute (a widely-established overseas institute to promote Chinese culture), Tomb Sweeping Day (a traditional Chinese festival to mourn the deceased), and Three Representatives (a requirement of the social responsibility on the part of the Chinese Communist Party members) can all be coded into this category.

Table 2. China English at the lexis level

\begin{tabular}{llll}
\hline Transliteration & Tuhao & Chengguan & Dama \\
\multirow{2}{*}{ Loan translations } & Confucius & Tomb & Three \\
& Institute & Sweeping Day & Representatives \\
\hline
\end{tabular}

\subsection{Syntax}

It is universally acknowledged that the major distinction between Chinese and English lies in the fact that English lays its emphasis on hypotaxis whilst Chinese is centered on parataxis (see He, 1999; Hu, 2007; Jiang, 1995; Jiang, 2002). Specifically, the structure of English syntax resembles a 'tree-type' the branches of which are produced from the stem and the twigs are extended from its branches. On the other hand, Chinese syntax is structured in a way that is akin to the development of bamboo, of which each upper segment comes out on the basis of the growing of the lower ones, and therefore, should be termed 'bamboo-type'. Constructed within the foregoing differing configurations, English sentences are seemingly loose but actually well-knitted and China English is terse and abundant in parallel structure. The salience of the Chinese syntax feature is inevitably exercised on its English equivalents, for example, seeking truth from facts (an extract from Chairman Mao's political reports), long time no see (a typical Chinglish that has evolved into China English), and safety is first and prevention is most (a slogan frequently seen in the Chinese manufacturing enterprises).

Table 3. China English at the syntax level

\begin{tabular}{llll}
\hline Standard & (No equivalent) & $\begin{array}{l}\text { I haven't seen } \\
\text { English }\end{array}$ & Keep alert! \\
China & Seeking truth & Long time no & Safety is first and \\
English & from facts. & see! & prevention is most. \\
\hline
\end{tabular}

\subsection{Discourse}

It is pervasively held by scholars that interaction with English under Asian context could possibly generate two outcomes: 'Englishization of the local languages' and 'nativization of English' (Kachru, 1995; Kachru, 2005; Kirkpatrick, 2002). China English is a case with no exception. Specifically, China English is borne with certain exclusive discourse features under the impact of the Chinese language. Researchers maintain that English discourses are predominantly composed by a deductive means; or rather they follow a general-specific pattern, whilst Chinese prints are primarily encoded in an inductive manner (Samovar \& Porter, 2004; Scollon \& Scollon, 1991; Young, 1982). As is perceived in a multitude of Chinese discourses, oftentimes it is after the presentation of considerable details and background information that the main point ultimately comes into the landscape. This literacy practice easily finds its way into the English translations and thus China English is fundamentally subject to this writing mode. Due to the nature of discourse and the space constraint, examples regarding this dimension of the linguistic features will be excluded in this article.

\section{Pedagogical Implications for Chinese EFL Teaching Context}

In accordance with Lin and David's (2001) survey study of Chinese learners' and teachers' language beliefs towards English, although the mastery of English faculties is highly valued amongst both the students and instructors, the 'put exams first'(Lin \& David, 2001, p. 401) ideology is deeply ingrained on the respondents' part. This examination-oriented culture leads to an instruction methodology running counter to the CLT approach and further marginalizes the implementation of China English. Under this impact, the present teaching paradigm yields batches of English-mute learners and consequently undermines efficiency in cross-culture encounters. Worse more, the phenomenon of culture aphasia (cited in Li, 2009) arises. To redress the language teaching deficiency in question, a new pedagogical ideology should be shaped and varied measures need to be taken by all sides involved.

First and foremost, the educational administrative sections should enact systematic policies of protecting and inheriting our culture heritages through teaching practice so as to authorize the integration of Chinese culture into the English curricula (Wang, 2000; Wang \& Ma, 2002). In Mckay's (2012, p. 40) words, the goal of English learning is 'not to learn primarily about the culture of English-speaking countries but rather to learn about many cultures and about differing cultural values as a way of increasing the learners' sensitivity to cross-culture differences.' As positive reactions, both the syllabus serving as an orienting frame for language education and textbooks which have displayed persistent authority in literacy instruction should be provisioned with Chinese culture content. The widely-held belief is that by supplementing local 
culture into EFL teaching materials and instructional activities, learners' sense of ownership of English will be stimulated and their motivation can be dramatically boosted (Li, 1993; Wang \& Ma, 2002; Wang, 2000).

Secondly, efforts should be made to initiate more culture forms so that Chinese culture would be embedded in various available prints and media resources (Jiang, 2002; Li, 1993; Wang, 2000). Apart from textbooks, websites, TV channels, newspapers and the like, more accessible sources should be developed to enable learners to experience local culture within an English context. Students can be assigned to collect relevant culture information in alignment with textbook theme units and present the tangible outcomes via multiple avenues.

Instead of solely emphasizing students' linguistic repertoire in terms of Standard English, more light should be shed on the testing of students' cross-culture awareness and socio-cultural competence. Thus the third feasible measure frequently recommended is to adjust and amend the assessment mechanism accordingly ( $\mathrm{Hu}, 2007$; Li, 1993; Wang, 2000).Through both formative and summative assessment systems, students' proficiency in using China English is expected to be promoted and enhanced. It is acknowledged by scholars that balanced development of students' linguistic capability and cross-culture communicative competence would generate fruitful results in terms of the advancement of China English ( see Hu, 2007; Jiang, 1995; Yan, 2002) .

\section{Future Research Trends and Directions}

Based on the overview of the previous prints tackling the subject matter of China English, it is not irrational to conclude that the study of China English is still in its infancy and there is enormous scope for the development in this realm.

As a starter, although an array of experts have been confirming the acceptability of China English, there is still a lack of empirical evidence to prove its objective existence and intelligibility. Thus more future experimental studies aimed at finding out language speakers' and users' attitude and belief towards China English are expected to be conducted. Besides, the extent to which China English can be accepted and comprehended in the vast majority also needs to be identified by means of a quantitative analysis.

Meanwhile, as can be clearly noted that studies of China English are predominantly undertaken by several Chinese scholars and most of these studies are centered on the discrimination of China English from Chinglish, consequently it has not evolved into a global and systematic research mechanism. In particular, studies at the syntactic and discourse levels of China English are unsubstantial and inadequate, and thus in need of wider and deeper research.

Additionally, despite theorists' contributions, the border between China English and Chinese English is still fuzzy, expressions such as 'You go first!'(which means 'After you.') and 'I very like you.' are deemed as a truncated use of English and therefore keep wandering around the gate of
China English, whilst are rejected by Chinese English in the meantime since many foreigners are tolerant to these 'Chinese-flavored' renderings. Professional understanding of this issue is expected to illuminate this area.

A fourth key direction for further development is to enrich and replenish the China English corpus given that its systematic establishment will provide a solid foundation for quantitative analysis of China English.

Finally, the integration of China English into the curriculum syllabus deserves fuller study. Actually, when it comes to the execution of China English instruction, there is a myriad of issues that call for a judicious consideration. Hesitations such as what is the extent to which China English should be merged into the present English curriculum (for example, should the phonological and discourse features of China English also be encouraged and promoted in class)? How should we reconcile China English and Standard English when confronted with the present overwhelming adherence to the latter? Between China English and Standard English, which teaching model should we adopt in different phases of EFL teaching?, etc. All these doubts remain unresolved and await illuminating insights.

\section{Conclusion}

The existence of China English has been acknowledged by both the domestic and foreign scholars in recent decades regarding its distinctive linguistic features and influential power in the current cross-culture communication. Despite the mounting popularity and acknowledgement of China English, the study of it is still in its infancy. Moreover, the implementation of China English into the present Chinese EFL teaching context is hindered by both the long-existing pedagogical ideology and other practical constraints. To further promote its status amongst global Englishes and enforce the ultimate integration into the teaching curriculum, China English awaits systematic and deeper research and more enlightening perspectives in this realm.

\section{References}

[1] Bliss, A. J. (1966). A Dictionary of foreign words and phrases in current English. New York: Dutton.

[2] Bolton, K. (2003). Chinese Englishes: A sociolinguistic history. Cambridge: Cambridge University Press.

[3] Deterding, D. (2006). The pronunciation of English by speakers from China. English World-Wide, 27, 175-198.

[4] Gao, L. W. (2001). The lexical acculturation of English in the Chinese context. Studies in the Linguistics Sciences, 31, 73-78.

[5] Ge, C. G. (1980).Mantan hanyiying wenti (Random thoughts on some problems in Chinese-English translation). Fanyi Tongxun(Chinese Translator's Journal),2, 1-8.

[6] He, D. Q., \& David, C. (2009). Language attitudes and linguistic features in the 'China English' debate. World Englishes, 28, 70-89. 
[7] He, Z. X. (1999). Zhongguo meiti gongye de fazhan lishi (The development history of the media industry in China). Shanghai: Fudan University Publishing House.

[8] Hu, X. Q. (2007). Quanqiu yingyu de fazhan qushi ji dui yingyu jiaoxue de qishi (The development of global English and its implications for English teaching). Guowai Waiyu Jiaoxue (Foreign Languages Teaching), 2, 16-20.

[9] Jiang, Y. J. (1995). Chinglish and China English. English Today, $11,51-53$.

[10] Jiang, Y. J. (2002). China English: issues, studies and features. Asian Englishes, 5, 4-23.

[11] Jiang, Y. J., \& Du, R. Q. (2003). Youguan 'zhongguo yingyu' de wenti (Issues on 'China English'). Waiyu Jiaoxue (Foreign Language Education), 24, 27-35.

[12] Jin, H. K. (2002). Hanying kuawenhua jiaoji fanyi zhong de zhongguo yingyu (China English in the intercultural translation between Chinese and English).Guangdong Zhiye Jishu Shifan Xueyuan Xuebao (Journal of Guangdong Polytechnic Normal University), 2, 72-78.

[13] Kachru, B. B. (1992). The other tongue: English across cultures. Chicago: University of Illinois Press.

[14] Kachru, Y. (1995). Contrastive rhetoric in world Englishes. English Today, 11, 21-31.

[15] Kirkpatrick, A.,\&Xu, Z. C. (2002). Chinese pragmatic norms and 'China English'. World Englishes, 21, 269-279.

[16] Kirpatrick, A. (2007b). World Englishes: Implications for international communication and English language teaching. Cambradge: Cambridge University Press.

[17] Li, W. Z. (1993). Zhongguo yingyuyu zhongguoshi yingyu (China English and Chinglish).Waiyu Jiaoxue Yu Yanjiu (Foreign Languages Teaching and Research), 4, 18-24.

[18] Li, Y. L. (2009). An analysis of the phenomenon of "native culture aphasia" in foreign language teaching and learning in China. Jilin Shifan Daxue Xuebao Shekeban (Journal of Jilin Normal University (Humanities \& Social Science Edition)), 4, 108-110.

[19] Lin, P., \& David, B. (2011). English as a "global language" in
China: An investigation into learners' and teachers' beliefs. Science Direct, 39, 391-402. Mawson, S. C. O. (1975). Dictionary of foreign terms. New York: Crowell.

[20] Mckay, S. L. (2012). Principles of teaching English as an international language. In L. Alsagoff, S. McKay, G. Hu, \& W. Renanyda (Eds.), Principles and practices for teaching English as an international language (pp. 28-46). New York: Francis and Taylor.

[21] Niu, Q., \& Wolff, M. (2003).China and Chinese, or Chingland and Chinglish? English Today, 19, 9-11.

[22] Pan, Z. X. (2002). Zhongguo yingyu bianti de yanjiu (A study of variations of China English).Waiyu Yanjiu (Foreign languages research), 6, 32-39.

[23] Samovar, L. A., \& Porter, R. E. (2004).Communication between cultures. Belmont, CA: Thomson/Wadsworth.

[24] Scollon, R., \& Scollon, S. (1991).Topic confusion in English-Asian discourse. World Englishes, 10, 113-21.

[25] Wang, N. S. (2000).Hanying fanyizhong de CHINGLISH (On CHINGLISH in Chinese-English translation).Zhongguo Fanyi (Chinese Translators Journal), 2, 31-35.

[26] Wang, R. P. (1991). Zhongguo yingyu shi keguan cunzai de (China English is an objective reality). Jiefangjun Waiyu Xueyuan Xuebao (Journal of PLA Foreign Languages Institute), $1,1-8$.

[27] Wang, W. B. \& Ma, D. (2002). Zhongshi yingyu he biaoda (Chinese English and its expressions). Dalian Daxue Xuebao (Journal of Dalian Nationalities University),14, 55-8.

[28] Widdoeson. (1994). The ownership of English. TESOL Quarterly, 28, 377-388.

[29] Yan, Z. Q. (2002). Shijie yingyu jianjie (An introduction to world Englishes). Beijing: Foreign Language Teaching and Research Press. Young, L. W. L. (1982). Inscrutability revisited. In J. J. Gumperz (Ed.), Language and social identity (pp. 72-84).Cambridge: Cambridge University Press.

[30] Zhuang, Y. C. (2000). Ye tan zhongshi yingyu (Guard against Chinglish). Zhongguo Fanyi (Chinese Translators Journal), 6, 7-10. 